\title{
QUALIDADE DE VIDA NO TRABALHO (QVT): UM ESTUDO COM PROFESSORES DOS INSTITUTOS FEDERAIS
}

\author{
R. R. OLIVEIRA ${ }^{1 *}$, I. B. SILVA ${ }^{2}$, D. S. P. CASTRO ${ }^{3}$ e A. C. LIMONGI-FRANÇA ${ }^{2}$ \\ ${ }^{1}$ Instituto Federal de Educação, Ciência e Tecnologia de São Paulo - Campus Sorocaba \\ ${ }^{2}$ Universidade de São Paulo \\ ${ }^{3}$ Faculdade de Gestão e Negócios, Universidade Metodista de Piracicaba \\ rodrigoribeirosp@hotmail.com*
}

Artigo submetido em outubro/2013 e aceito em novembro/2015

DOI: $10.15628 /$ holos.2015.1726

\section{RESUMO}

No cenário atual em que há exigências contínuas de evolução do conhecimento e de avanços tecnológicos, a educação tecnológica é um assunto que merece destaque, pois é através dela que uma grande parcela dos trabalhadores é formada para atuar no mercado de trabalho cada vez mais qualificado e competitivo. Um dos projetos estratégicos mais importantes na área de ensino no país é o dos Institutos Federais que contam com 562 campi em todo país. Houve um crescimento significativo do quadro funcional: no ano de 2002 contava com 8.999 professores, atualmente conta com 37.021 (2015). Isso mostra um crescimento de $411,39 \%$. Nesse contexto, o objetivo deste trabalho foi analisar o grau de satisfação dos professores dos Institutos Federais em relação à Qualidade de Vida no Trabalho, diante dos impactos da expansão da rede no Brasil. A pesquisa foi realizada com professores que participaram do II Fórum Mundial de Educação Profissional e Tecnológica, realizado em Florianópolis em 2012. Esta pesquisa caracteriza- se como quantitativa, exploratória, descritiva e avaliação (survey). Com relação ao instrumento, foi utilizado o Protocolo Biopsicossocial e organizacional - BPSO-96, de Limongi-França. Foram respondidos 43 questionários. Entre os cinco domínios avaliados, constatou-se que o domínio social foi o que apresentou o menor índice de satisfação $(3,193)$, enquanto que o domínio psicológico foi o que apresentou maior satisfação $(6,819)$. Destaca-se que a variável que apresentou a maior média na pesquisa foi a relação professor-aluno $(8,233)$. Embora os resultados não possam ser generalizados para o expressivo universo de professores do Ensino Técnico dos Institutos Federais, os achados deste estudo demonstram a necessidade de alinhamento quanto à política de gestão de benefícios e apoio familiar e comunitário no grupo pesquisado, revelando a qualidade da relação ensino-aprendizado neste cenário.

PALAVRAS-CHAVE: Professor de educação profissional e tecnológica; qualidade de vida no trabalho; Institutos Federais; Protocolo BPSO.

\section{QUALITY OF WORKING LIFE (QWL): A STUDY WITH TEACHERS FROM THE FEDERAL INSTITUTES}

\begin{abstract}
In the current scenario, where we have continuous demands for advances in both knowledge and technology, technological education is a subject which must be highlighted, because it is through this education a great part of the workforce is formed to take part in an increasingly competitive and qualified labor market. One of the most strategic projects in the teaching area in the country is that advanced by the Institutos Federais (Federal Institutes) having 562 campuses throughout the country. There was a significant growth in staff: in 2002 there were 8.999 teachers, now there are 37.021 (2015). This is a $411.39 \%$ increase. In this context, the objective of this study was to analyze the satisfaction showed by teachers working in the Federal Institutes according to Quality of Working Life, in face of the institutes' network expansion in Brazil. The research was conducted with teachers who participated in the II Fórum Mundial de Educação Profissional e Tecnológica, in
\end{abstract}

Florianópolis, 2012. This research is characterized as quantitative, exploratory, descriptive and evaluative (survey). With respect to the instrument, we used the Biosocial and organizational protocol - BPSO-96, by Limongi-França. There were 43 completed questionnaires. Among the 5 evaluated areas, we find the social area presented the lower index of satisfaction (3.193), while the psychological area presented the higher index (6.819). The teacher-student relationship stands out as the highest index (8.233). Although the results could not be generalized to the expressive universe of Technological Teaching in the Federal Institutes, this study's findings show the need of alignment concerning the policy of benefits management and of family and communitarian support in the group studied, showing the quality of the teaching-learning relationship in this scenario.

KEYWORDS: Technological and Professional education teacher; Quality of working life; Federal Institutes; BPSO protocol. 


\section{INTRODUÇÃO}

Estudos de base econômica têm demonstrado que, em média, os países que alcançam um alto nível de crescimento econômico são também aqueles que têm maiores taxas de alfabetização e investem continuamente para a melhoria da educação e da força de trabalho.

Na Europa, as taxas de retorno sobre o investimento em educação são de $7 \%$ a $8 \%$, sendo que em muitos países em desenvolvimento, podem ser muito maiores. O Brasil, por exemplo, apresenta taxa global da ordem de $12 \%$ a $14 \%$. Esses resultados positivos sugerem que investir em educação contribui para o crescimento econômico do país (CARNOY, 2006).

O Censo Escolar realizado pelo Instituto Nacional de Estudos e Pesquisas Educacionais (INEP) do Ministério da Educação aponta um crescimento no número de matrículas nos Institutos Federais $\Delta \% 2008 / 201489,2 \%$. Nesse período, o crescimento foi substancial, com uma expansão de 132.732 para 249.604 (BRASIL, 2015).

A retomada do crescimento econômico do país, o surgimento de um modelo de produção vinculado à intensa aplicação de ciência e tecnologia e a exigência de trabalho qualificado são fatores que aumentam a importância da formação escolar e profissional em todos os níveis. Nesse contexto, cabe destacar a importância da expansão da sua oferta e ampliação da rede de ensino para a educação profissional e tecnológica.

Diante disso, o tema da qualidade de vida no trabalho assume maior complexidade, pois não basta melhorar um aspecto para melhorar a educação como um todo. Se fosse fácil resolver o desafio da qualidade no ambiente de educação não se estaria discutindo esse tema no momento atual. Sua conquista depende de um conjunto de ações.

Pensando nessas questões, pode-se argumentar que existem lacunas a serem preenchidas e que devem ser consideradas e tratadas logo no início da implantação (expansão) e na manutenção dos campi dos Institutos Federais. De forma geral, considera-se de vital importância identificar e entender a percepção dos professores quanto à satisfação com a Qualidade de Vida no Trabalho, diante do impacto da expansão dos Institutos Federais de Educação, Ciência e Tecnologia.

\subsection{Problema da Pesquisa e Objetivo}

O emprego está em alta no país, segundo as pesquisas. A dificuldade está em preencher determinadas vagas oferecidas pelas empresas, em funções que exigem pessoal qualificado, principalmente técnicos especializados. Para crescer de forma sustentável o Brasil precisa formar novos profissionais e qualificar a mão de obra disponível (SÃO PAULO, 2012).

Os Institutos Federais atuam na capacitação de diferentes segmentos de mão de obra nacional, com oferta de cursos que vão desde a formação inicial até os de mestrado (BRASIL, 2013).

De 140 escolas em 2003, os Institutos Federais chegaram a 562 em 2014. Entre as unidades da federação que não tinham nenhuma estrutura de Institutos Federais e passaram a ter a rede estão: Mato Grosso do Sul, Amapá, Acre, Rondônia e Distrito Federal.

Em 2002 a rede contava com 8.999 professores, atualmente (2015) conta com 37.021. Isso mostra um crescimento de 411,39\% com a expansão (BRASIL, 2015). 
Nesse contexto, surge a necessidade de examinar a estrutura de funcionamento dos Institutos Federais, observando as oportunidades de melhoria em diversos fatores relacionados à oferta e à qualidade dos serviços educacionais prestados.

Segundo Bertuol e Martins (2009), a qualidade da ação pedagógica depende da qualidade de vida do professor.

Percebe-se que nos últimos anos em detrimento da perda de controle sobre o trabalho, sua intensificação e fragmentação colaboraram expressivamente para a precarização do trabalho e vem provocando doenças nos professores e comprometendo todo o processo de ensino e aprendizagem, já que esse profissional é a espinha dorsal desse processo.

Assim, a definição da situação-problema envolve os aspectos referentes à qualidade em educação e à gestão de pessoas, haja vista que não há condição de fazer gestão de qualidade de vida pelo modelo proposto.

O objetivo deste trabalho foi analisar o grau de satisfação dos professores da Rede Federal de Educação Básica, Técnica e Tecnológica em relação à Qualidade de Vida no Trabalho, diante dos impactos da expansão da Rede no Brasil. Analisaram-se os domínios biológico, psicológico, social, organizacional e as práticas docentes. A pesquisa foi realizada com os professores dos Institutos Federais que participaram do II Fórum Mundial de Educação Profissional e Tecnológica.

\section{REVISÃO BIBLIOGRÁFICA}

\subsection{Institutos Federais de Educação Ciência e Tecnologia}

A Lei 11.892, publicada em 29/12/2008, cria no âmbito do Ministério da Educação um novo modelo de instituição de educação profissional e tecnológica. Esse modelo foi estruturado a partir do potencial instalado nos Centros Federais de Educação Tecnológica (CEFETs), Unidades Descentralizadas de Ensino (UNEDs), Escolas Técnicas e Agrotécnicas Federais e Escolas vinculadas às Universidades Federais. Assim sendo, os Institutos Federais de Educação, Ciência e Tecnologia (IFET`s) criam e fortalecem condições estruturais essenciais para o desenvolvimento educacional, social e econômico do Brasil (BRASIL, 2008; PACHECO; SILVA, 2009). A Figura 1 mostra esse aspecto.

Diante dessa expansão sem precedentes, a proposição dos Institutos Federais de Educação, Ciência e Tecnologia, como modelo de reorganização das instituições federais de educação profissional e tecnológica tem como foco uma atuação integrada e referenciada regionalmente. A rede evidencia com grande nitidez os desejáveis enlaces entre educação sistêmica, desenvolvimento e territorialidade (BRASIL, 2007). 


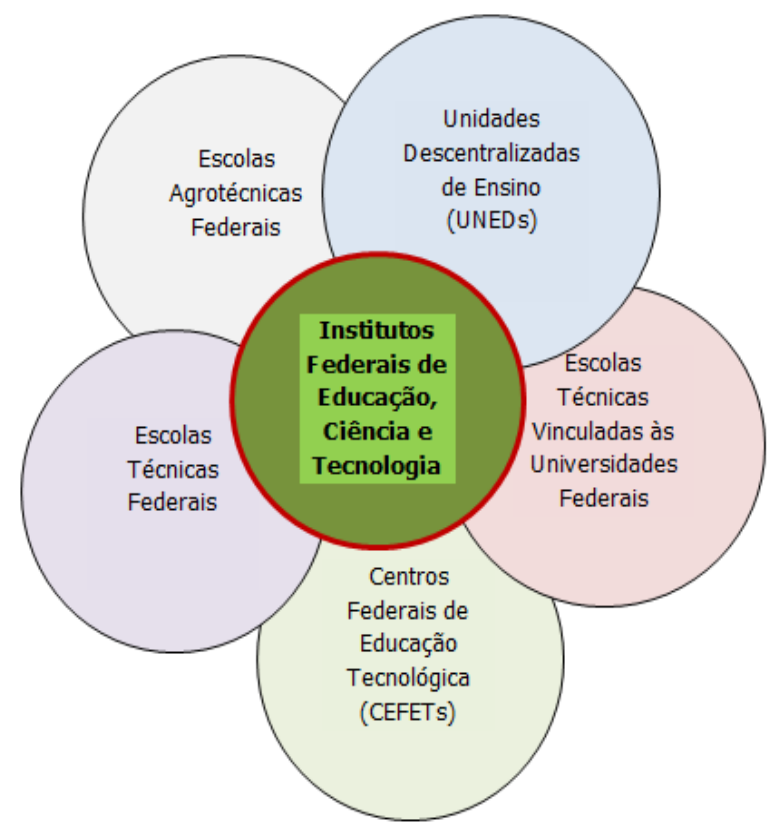

Figura 1: Novo modelo de instituição de educação profissional e tecnológica Fonte: Brasil, (2008); Pacheco; Silva, (2009)

A finalidade dos Institutos Federais é promover a justiça social, a equidade, o desenvolvimento sustentável com vistas à inclusão social, bem como a busca de soluções técnicas e a criar novas tecnologias. Os Institutos Federais devem responder de forma ágil e eficaz, às necessidades crescentes por formação profissional, por difusão de conhecimentos científicos e de suporte aos arranjos produtivos locais. Podendo atuar em todos os níveis e modalidades da educação profissional, com estreito compromisso com o desenvolvimento integral do trabalhador, devendo articular experiência institucional inovadora (PACHECO; SILVA, 2009).

\subsection{Professor do Ensino Técnico e Tecnológico}

Os professores da educação profissional aprenderam, e ainda aprendem, a ensinar fundamentos (técnica e metodologia) em sua ação profissional a partir de sua própria ação. Muitas vezes é pelo apreço, amor e pela dedicação que têm a uma determinada profissão. São estes saberes que fazem dele um profissional docente (SOARES, 2008).

No caso da educação profissional, uma boa parte do que os professores sabem sobre o ensino, sobre o seu papel e sobre como ensinar provém de sua própria história de vida. Isso evidencia que esses atributos possibilitam uma maior aproximação com os alunos. De origens sociais parecidas, com histórias de vida muito próximas, os professores identificam os estudantes, assim como a si mesmos, como batalhadores à procura de uma oportunidade e veem, no mundo do trabalho, o principal (ou o possível) canal de acesso a melhores condições de vida. O trabalho com educação profissional possibilita ao professor a oportunidade de colaborar para a melhoria da qualidade de vida de seus estudantes, melhoria esta que é, na classe trabalhadora, valor central de orientação de vida. (TARDIF, 2002; BURNIER, et al., 2007).

Parece que os professores da educação profissional são menos expostos ao que Tardif (2005) descreve como a possibilidade do objeto "aluno" neutralizar a ação do professor. Para o autor, o fato de a escolarização ser uma atividade obrigatória e a ação docente ser executada sobre 
uma coletividade, pode fazer com que, em alguns casos, esses alunos dificultem o trabalho do professor. Fato este que não ocorre no ensino profissional.

Quanto aos desafios que se apresentam aos professores que atuam ou desejam atuar nessa modalidade de ensino, nesta primeira década do século XXI, Machado (2008) destaca os seguintes:

- desafios relacionados às mudanças organizacionais que afetam as relações profissionais;

- desafios referentes aos efeitos das inovações tecnológicas sobre as atividades de trabalho e culturas profissionais;

- desafios que têm a ver com o novo papel que os sistemas simbólicos desempenham na estruturação do mundo do trabalho;

- desafios provenientes do aumento das exigências de qualidade na produção e nos serviços;

- desafios resultantes da exigência de maior atenção à justiça social, às questões éticas e de sustentabilidade ambiental.

O trabalho docente na educação profissional tem particularidades e dilemas. O mais latente talvez seja a presença constante da dualidade estrutural do trabalho manual versus trabalho intelectual que permeia as concepções de educação profissional presentes na história brasileira. Além disso, a constituição do ensino profissionalizante no Brasil, em diversos momentos históricos como formador de mão de obra para o capital faz com que a educação técnica seja frequentemente demonizada ou, em contrapartida, endeusada "como salvadora da economia nacional" (SILVA, 2010).

\subsection{Qualidade de Vida no Trabalho}

Sem uma qualidade de vida construída de forma enriquecedora, não se perpetua o progresso. A QVT combinada com programas de qualidade, compromissos com a inovação, resgatando talentos, limites e necessidades humanas, consolida a cultura competitiva (LIMONGIFRANÇA; RODRIGUES, 2009, p. 171).

Stephen e Dhanapal (2012) afirmam que a Qualidade de Vida no Trabalho de um indivíduo é tão importante quanto sua vida pessoal. A satisfação e contentamento em ambos os aspectos são muito importantes para manter a vida mais equilibrada. Uma desarmonia em um desses aspectos pode prejudicar o outro, gerando a insatisfação.

A construção da Qualidade de Vida no Trabalho, de acordo com Limongi-França (2009), ocorre a partir do momento em que se enxerga a pessoa como um todo. Este enfoque é conhecido como biopsicossocial. A autora explica que o conceito de biopsicossocial originou-se da Medicina Psicossomática que propõe uma visão integrada, holística do ser humano, em oposição à abordagem cartesiana, que divide o ser humano em partes. No mesmo estudo defini-se que "toda pessoa é um complexo biopsicossocial, ou seja, tem potencialidades biológicas, psicológicas e sociais que respondem simultaneamente às condições de vida". A partir dessa visão, deve-se trabalhar o que hoje conhecemos como domínios específicos. Esta expressão era conhecida como camada, critérios ou indicadores. No entanto, visando ao alinhamento das discussões no âmbito da Qualidade de Vida, passou-se a denominar essas competências como domínios, que serão definidos a seguir. 
O domínio biológico refere-se às características físicas herdadas ou adquiridas ao nascer e mantidas por toda a vida. Compreendendo metabolismo, resistências e vulnerabilidades dos órgãos ou sistemas. O domínio psicológico refere-se aos processos afetivos, emocionais e de raciocínio conscientes ou inconscientes que formam a personalidade de cada pessoa e o seu modo de perceber e posicionar-se diante dos demais e das circunstâncias que vivencia. $O$ domínio social revela os valores, as crenças, o papel na família, no trabalho e em todos os grupos e comunidades a que cada um pertence e participa. O meio ambiente e a localização geográfica também formam a dimensão social. Visando integrar o conceito com elementos do trabalho em organizações, desenvolveu-se o domínio organizacional, que se refere à cultura organizacional, porte da empresa, tecnologia, segmento econômico em que atua e padrões de competitividade (LIMONGI FRANÇA 2010).

O conjunto desses domínios forma a visão de pessoa no trabalho: BPSO, em contínua interação, interdependência, mas como processos intrínsecos e extrínsecos próprios, conforme a Figura 2.

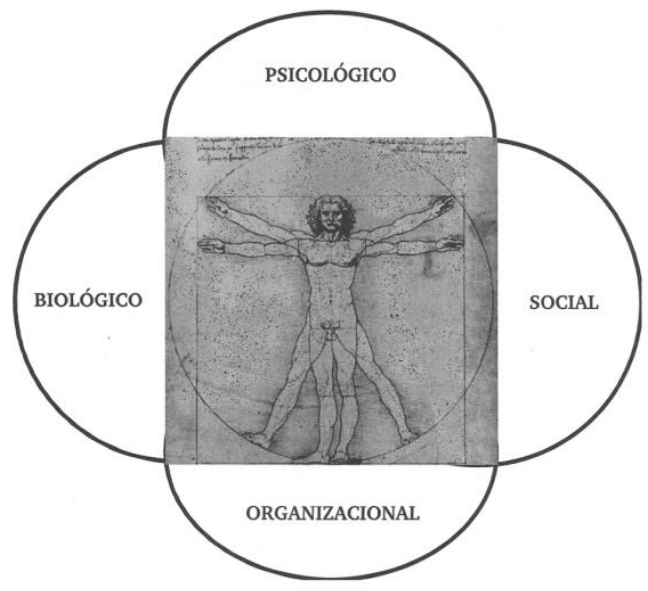

Figura 2: A visão de pessoal BPSO Fonte: Limongi-França, (2009)

Sobre os indicadores das variáveis de Qualidade de Vida no Trabalho, Limongi-França (1996) esclarece que são ferramentas de planejamento e decisão que permitem clareza de critérios. A não ambiguidade de avaliação, facilidades de levantamento, de compreensão e de comparação. Explica ainda que outros critérios podem ser utilizados para a seleção de indicadores, tais como crenças pessoais, qualidade pessoal da vida, qualidade das relações sociais, qualidade da vizinhança e padrão internacional da qualidade de vida.

Limongi-França (1996) revela que para a criação de seu instrumento de pesquisa BPSO-96, baseou-se nos conceitos de Walton (1975) que propôs, em sua opinião, o mais completo conjunto de critérios e indicadores de qualidade de vida. A autora fundamentou-se também no conjunto de indicadores do Índice de Desenvolvimento Social (IDS) e no Índice de Desenvolvimento Humano (IDH).

O IDS é composto pelos indicadores de esperança de vida, grau de alfabetização, distribuição de renda. Já o IDH é constituído pelos seguintes indicadores: alimentação, saúde, seguro de vida, conhecimento, condições de trabalho, segurança contra o crime, lazer, participação econômica, participação cultural e política. 
Walton (1975) observou as necessidades básicas e secundárias do ser humano, bem como as condições da organização e, a partir de seus estudos, propôs indicadores empresariais que, se implementados pela empresa, podem evidenciar a construção de Qualidade de Vida no Trabalho (OLIVEIRA, 2003; OLIVEIRA, 2008).

O modelo BPSO acima descrito foi utilizado para avaliar a satisfação da qualidade de vida no trabalho dos professores dos Institutos Federais, através do protocolo com indicadores agrupados de acordo com cada domínio descrito e com escala para registro da percepção sobre os diversos aspectos integrados do seu bem-estar pessoal e profissional.

\section{METODOLOGIA}

\subsection{Pesquisa Quantitativa (survey)}

A pesquisa quantitativa teve início no II Fórum Mundial de Educação Profissional e Tecnológica que aconteceu no período de 28 de maio a 10 de junho de 2012 em Florianópolis, Santa Catarina - Brasil. Esse evento contou com a participação de aproximadamente 26.700 pessoas, entre professores, estudantes, representantes da sociedade civil e de governos de 30 países.

Com a estratégia de otimizar os esforços, o pesquisador, posicionou-se na recepção da tenda de apresentação dos pôsteres que abrigaria os trabalhos de 2.660 pesquisadores. A abordagem deu-se através de uma pergunta feita pelo pesquisador: $\mathbf{O}$ (a) senhor(a) faz parte do quadro de professores efetivos do Instituto Federal? Caso a resposta fosse positiva, explicava-se que se tratava de uma pesquisa, o seu propósito e que seria importante a participação dos professores dos diversos campi. Em seguida, solicitava-se o endereço eletrônico (e-mail) do(a) professor(a) para que lhe fosse enviado o link e o questionário eletrônico para preenchimento. Não houve recusa dos professores em participar da pesquisa. A dificuldade encontrada foi o ruído do ambiente, que prejudicou a comunicação entre os professores e o pesquisador. Durante os dias 30 e 31 de maio e 1 o de junho de 2012, nos períodos das 7 h30 às 11 h00 e das $13 \mathrm{~h} 30$ às $18 \mathrm{~h} 45$ foram colhidos 159 e-mails de professores dos mais diversos campi dos Institutos Federais.

Vale destacar algumas respostas que chamaram a atenção do pesquisador, quando em sua abordagem perguntava: $O$ (a) senhor(a) faz parte do quadro de professores efetivos do Instituto Federal? Surgiam algumas respostas como: ...quem dera,...ainda não, deixando claro que para alguns participantes do evento, ser professor do Instituto Federal é algo a ser alcançado e desejado.

Dos 159 (cento e cinquenta e nove) e-mails encaminhados, 14 (quatorze) foram rejeitados pelos destinatários, restando 145 (cento e quarenta e cinco) válidos. Foram respondidos 43 (quarenta e três) no período de 30 de agosto a 06 de setembro de 2012. Conseguiu-se o percentual aceitável de $29,65 \%$ de retorno dos questionários.

Segundo Marconi e Lakatos (2009), em média, os questionários expedidos pelo pesquisador alcançam $25 \%$ de devolução. Obteve-se, portanto, um percentual de retorno um pouco acima do constatado pelos autores. 


\section{ANÁLISE E DISCUSSÃO DOS RESULTADOS}

\subsection{Dados Demográficos}

A Tabela 1 apresenta uma síntese do perfil geral dos professores pesquisados na fase de caracterização dos sujeitos.

Tabela 1: Demonstrativo geral do perfil dos professores.

\begin{tabular}{|c|c|c|}
\hline Caracterização & Perfil/Prevalência & $\%$ \\
\hline Gênero & Feminino & 55,80 \\
\hline Titulação & Mestrado & 55,81 \\
\hline Carga horária & Dedicação exclusiva & 97,70 \\
\hline Idade & De 12 a 24 & 60,47 \\
\hline Estado civil & Até 40 anos & 67,45 \\
\hline Atuação como professor(a) & De 05 a 15 anos & 53,49 \\
\hline $\begin{array}{c}\text { Atuação como professor(a) no } \\
\text { Instituto Federal }\end{array}$ & Até 03 anos & 53,49 \\
\hline Dependentes & Até 02 & 55,82 \\
\hline $\begin{array}{c}\text { Tempo semanal despendido } \\
\text { fora do campus com trabalhos } \\
\text { ligados à atividade docente }\end{array}$ & De 8 a 20 horas & 39,54 \\
\hline Turno de trabalho & Vespertino & 93,03 \\
\hline Condições de acesso ao campus & Regular & 39,53 \\
\hline $\begin{array}{c}\text { Proximidade entre a moradia e } \\
\text { o local de trabalho (campus) }\end{array}$ & Boa & 39,53 \\
\hline Status familiar & Chefe de família & 65,10 \\
\hline Área de Ensino & Técnica & 51,20 \\
\hline $\begin{array}{c}\text { Situação sindical } \\
\text { sindicalizados }\end{array}$ & 55,80 \\
\hline
\end{tabular}

Fonte: Dados da pesquisa

\subsection{Instrumento de Pesquisa}

O questionário para esta pesquisa foi construído a partir do protocolo BPSO-96 (biopsicossocial e organizacional) de Limongi-França que é validado na cultura brasileira e possui abrangência de indicadores.

\subsection{Análise Descritiva}

A análise dos dados referentes às questões respondidas pelos professores não deve ser feita a partir de proporção, visto que a escala utilizada não é qualitativa. O que se tem é uma medida que, quanto mais próxima de 1 revela um grau de insatisfação e quanto mais próxima de 10, um grau de satisfação.

A seguir, são apresentados os resultados e as respectivas análises da pesquisa de campo. Foram destacadas em "Iaranja" as variáveis que apresentaram médias menores que 5 e em "verde" as iguais ou maiores que sete. 


\subsubsection{Domínio Biológico}

A Tabela 2 apresenta as médias das escalas do domínio biológico. A questão Q18 - Atuação da Comissão Interna de Prevenção de Acidentes (CIPA) do Campus, reflete uma média de 3,093, a mais baixa de satisfação.

Este resultado sugere que "as organizações devem gerir programas consistentes de prevenção contra os riscos ocupacionais, tais como físicos, químicos, biológicos, ergonômicos e de acidentes, de acordo com a própria norma reguladora (NR5), que rege esta questão" (STEFANO, 2006).

Em relação ao domínio biológico, os professores estão insatisfeitos com as seguintes questões: atendimento ambulatorial no campus; qualidade da alimentação servida no campus; qualidade dos programas de preservação da vida e da integridade física, bem como com a promoção da saúde dos servidores e dos alunos.

Tabela 2: Variáveis do Domínio Biológico.

\begin{tabular}{|c|c|c|c|c|}
\hline \multirow{2}{*}{ Variáveis do Domínio Biológico } & \multirow{2}{*}{ Média } & \multirow{2}{*}{$\begin{array}{c}\text { Erro } \\
\text { Padrão }\end{array}$} & \multicolumn{2}{|c|}{ IC de $95 \%$ de confiança } \\
\hline & & & $\mathrm{LI}$ & LS \\
\hline $\begin{array}{l}\text { Q14 - Controle do campus dos riscos } \\
\text { ergonômicos (esforço físico, } \\
\text { levantamento de peso, postura } \\
\text { inadequada) e ambientais }\end{array}$ & 5,140 & 0,376 & 4,403 & 5,876 \\
\hline $\begin{array}{l}\text { Q15 - Atendimento ambulatorial no } \\
\text { campus (atender às questões de saúde } \\
\text { da comunidade do campus) }\end{array}$ & 4,442 & 0,438 & 3,583 & 5,301 \\
\hline $\begin{array}{l}\text { Q16 - Atendimento do plano de saúde } \\
\text { (internações, consultas, exames, etc.) }\end{array}$ & 5,581 & 0,372 & 4,851 & 6,311 \\
\hline $\begin{array}{l}\text { Q17 - Qualidade da alimentação servida } \\
\text { no campus (espaço físico para a } \\
\text { alimentação, qualidade do alimento: } \\
\text { balanceado, variado, etc.) }\end{array}$ & 3,884 & 0,432 & 3,038 & 4,730 \\
\hline $\begin{array}{c}\text { Q18 - Atuação da Comissão Interna de } \\
\text { Prevenção de Acidentes (CIPA) do } \\
\text { Campus }\end{array}$ & 3,093 & 0,381 & 2,347 & 3,839 \\
\hline $\begin{array}{l}\text { Q19 - Qualidade dos programas de } \\
\text { preservação da vida e da integridade } \\
\text { física, bem como com a promoção da } \\
\text { saúde dos servidores e dos alunos }\end{array}$ & 3,651 & 0,366 & 2,934 & 4,368 \\
\hline Média & 4,300 & 0,168 & 3,968 & 4,629 \\
\hline
\end{tabular}

Fonte: Dados da pesquisa.

\subsubsection{Domínio Psicológico}

Relativamente às questões que compõem o domínio psicológico, infere-se pelos resultados apresentados na Tabela 3, que os professores encontram-se satisfeitos.

O resultado, de acordo com o intervalo de confiança, apresentou o limite inferior de 6,527 e o superior de 7,110 enquanto a média foi de 6,819. De acordo com a Tabela 3, a Q20 foi a que apresentou a maior média.

Tabela 3: Variáveis do Domínio Psicológico. 


\begin{tabular}{|c|c|c|c|c|}
\hline \multirow{2}{*}{ Variáveis do Domínio Psicológico } & \multirow{2}{*}{ Média } & \multirow{2}{*}{ Erro Padrão } & \multicolumn{2}{|c|}{ IC de $95 \%$ de confiança } \\
\hline & & & $\mathrm{LI}$ & LS \\
\hline $\begin{array}{l}\text { Q20 - Confiança nos critérios de seleção dos } \\
\text { professores (concurso público e/ou processos } \\
\text { seletivos simplificados) }\end{array}$ & 7,558 & 0,281 & 7,007 & 8,109 \\
\hline $\begin{array}{l}\text { Q21 - Forma de avaliação do desempenho para } \\
\text { progressão funcional }\end{array}$ & 6,535 & 0,328 & 5,891 & 7,178 \\
\hline $\begin{array}{l}\text { Q22 - Clima de camaradagem com os } \\
\text { professores da área técnica }\end{array}$ & 7,395 & 0,285 & 6,838 & 7,953 \\
\hline $\begin{array}{l}\text { Q23 - Clima de camaradagem com os } \\
\text { professores do núcleo comum }\end{array}$ & 7,302 & 0,289 & 6,735 & 7,869 \\
\hline $\begin{array}{l}\text { Q24 - Satisfação com a } \\
\text { remuneração/vencimento }\end{array}$ & 5,302 & 0,358 & 4,601 & 6,003 \\
\hline Média & 6,819 & 0,149 & 6,527 & 7,110 \\
\hline
\end{tabular}

Fonte: Dados da pesquisa.

\subsubsection{Domínio Social}

Na Tabela 4 são apresentadas as médias das escalas que compõem o domínio social.

Neste domínio, observa-se que a média mais baixa de satisfação foi de 2,047, referente à Q31-Valor do auxílio transporte.

Tabela 4: Variáveis do Domínio Social.

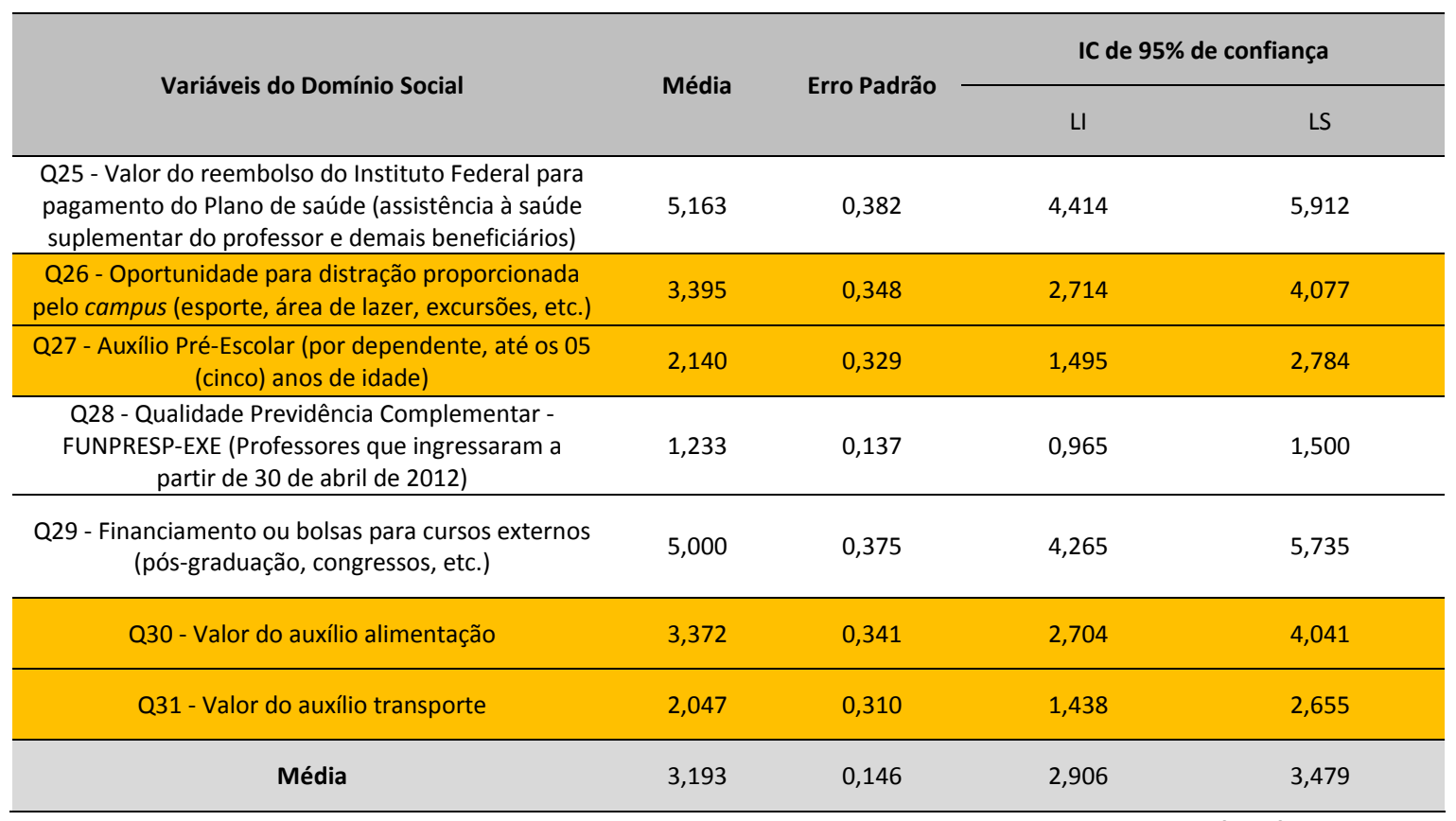

Fonte: Dados da pesquisa.

Com relação a este domínio, verifica-se certo nível de insatisfação dos professores conforme se observa nos resultados apresentados nas seguintes questões: Q27-Auxílio Pré-Escolar (por dependente, até os cinco anos de idade) que reflete uma média de 2,140; a Q30-Valor do auxílio alimentação, que apresentou a média de 3,372 e a Q26-Oportunidade para distração proporcionada pelo campus (esporte, área de lazer, excursões, etc.), que apresentou a média de 3,395 . 


\subsubsection{Domínio Organizacional}

A Tabela 5 apresenta as médias das escalas do domínio organizacional.

Pode-se observar que as média mais altas de satisfação foi obtida pela questão Q9 Programas sociais destinados aos alunos carentes, e pela Q6 - Atuação do departamento de Recursos humanos/Gestão de pessoas no campus. Em ambas as questões a média foi superior que sete.

De forma geral, conforme se verifica na Tabela 5, é possível inferir que os respondentes encontram-se parcialmente satisfeitos.

Tabela 5: Variáveis do Domínio Organizacional.

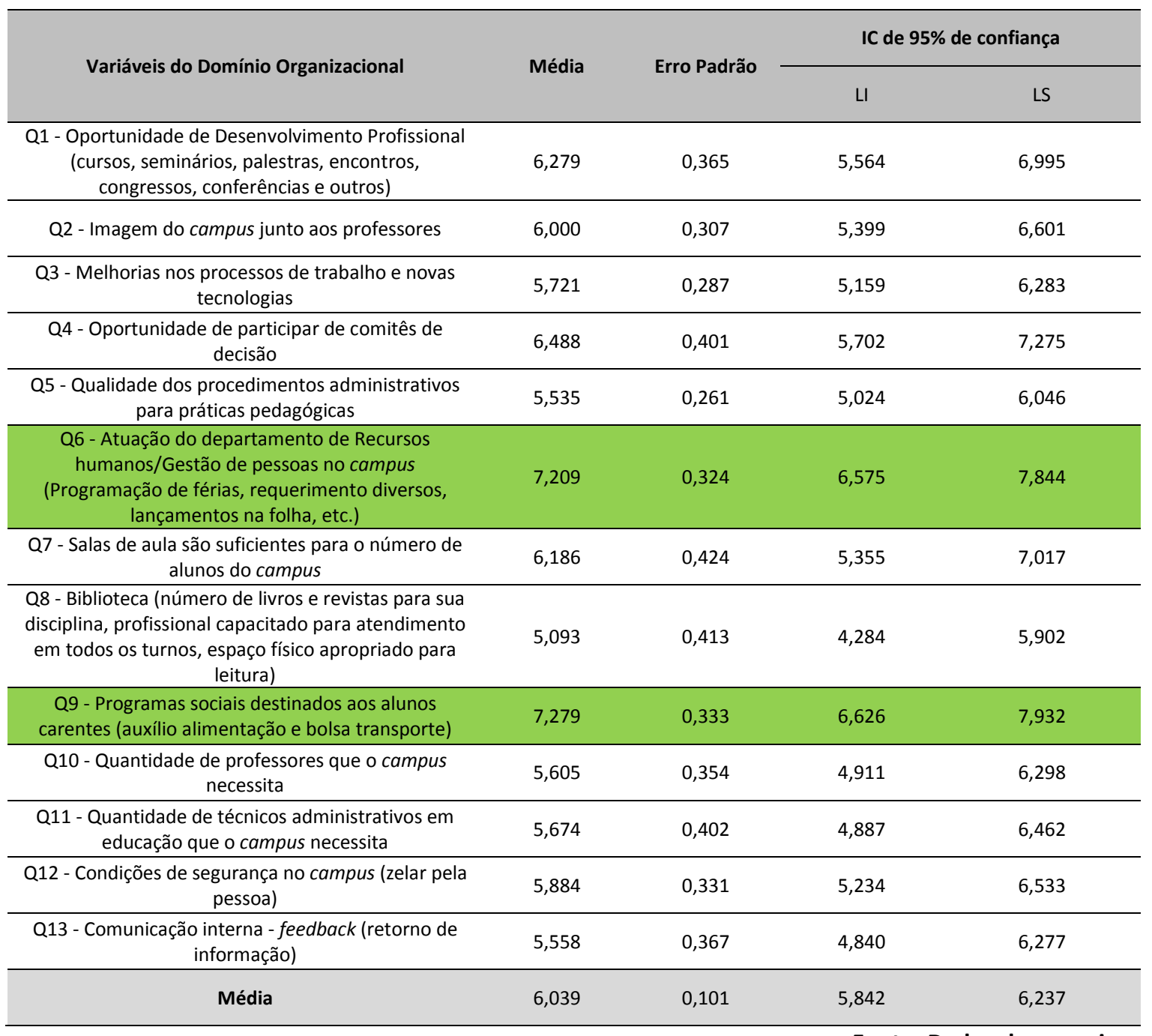

Fonte: Dados da pesquisa.

\subsubsection{Domínio Organizacional - Atividade Docente}

Fazem parte deste domínio as seguintes variáveis: (i) boas condições de trabalho que inclui os espaços educativos organizados, limpos, arejados, agradáveis, cuidados; (ii) móveis, equipamentos e materiais didáticos adequados à permanência do professor e que favoreçam o convívio entre seus pares e alunos; (iii) oferta de ambientes propícios para realização do ensino, pesquisa e extensão proporcionando uma prestação de serviços de qualidade aos alunos, aos pais dos alunos e à comunidade. 
A Tabela 6 apresenta as médias das escalas do domínio organizacional inerentes às atividades docentes.

Verifica-se que a média mais alta quanto à satisfação é em relação à Q40-relação professoraluno, que apresentou uma média de 8,233.

As médias mais baixas quanto à satisfação foram verificadas nas questões Q33 - Os laboratórios atendem às necessidades dos cursos ofertados pelo campus e Q41 - ambiente de descanso dos professores. As médias obtidas foram, respectivamente, 4,349 e 4,977.

Tabela 6: Variáveis do Domínio Organizacional - Atividade Docente.

\begin{tabular}{|c|c|c|c|c|}
\hline \multirow{2}{*}{$\begin{array}{c}\text { Variáveis do Domínio Organizacional - Atividade } \\
\text { Docente }\end{array}$} & \multirow{2}{*}{ Média } & \multirow{2}{*}{ Erro Padrão } & \multicolumn{2}{|c|}{ IC de $95 \%$ de confiança } \\
\hline & & & $\mathrm{LI}$ & LS \\
\hline Q32 - Quantidade de alunos por sala de aula & 7,047 & 0,360 & 6,341 & 7,752 \\
\hline $\begin{array}{l}\text { Q33 - Os laboratórios atendem às necessidades dos } \\
\text { cursos ofertados pelo campus (quantidade, } \\
\text { tamanho, segurança, equipamentos, etc.) }\end{array}$ & 4,349 & 0,389 & 3,586 & 5,112 \\
\hline $\begin{array}{l}\text { Q34 - O campus incentiva a produção científica } \\
\text { (Acesso ao Portal de Periódicos da CAPES, bolsa para } \\
\text { alunos, redução de carga horária didática do } \\
\text { professor pesquisador) }\end{array}$ & 5,279 & 0,400 & 4,495 & 6,063 \\
\hline $\begin{array}{c}\text { Q35 - Qualidade dos equipamentos (televisão, } \\
\text { aparelho de som, retroprojetor, data show, vídeo, } \\
\text { DVD, projetor de slides, microfone, etc.) }\end{array}$ & 6,488 & 0,370 & 5,764 & 7,213 \\
\hline $\begin{array}{l}\text { Q37 - Salas de aula em boas condições (iluminação, } \\
\text { ventilação, ruído, temperatura, mobília) }\end{array}$ & 6,302 & 0,399 & 5,521 & 7,084 \\
\hline $\begin{array}{l}\text { Q38 - Mesa e cadeira adequada para uma boa } \\
\text { postura do professor em sala de aula }\end{array}$ & 5,860 & 0,399 & 5,079 & 6,642 \\
\hline Q39 - Hora aula semanal & 6,605 & 0,352 & 5,914 & 7,295 \\
\hline Q40 - Relação professor-aluno & 8,233 & 0,223 & 7,796 & 8,669 \\
\hline Média & 6,072 & 0,125 & 5,827 & 6,316 \\
\hline
\end{tabular}

\subsection{Resumo dos Domínios}

No domínio organizacional, as questões com médias superiores a sete foram a Q6 $(7,029)$ e a Q9 $(7,279)$.

No domínio biológico as questões que apresentaram médias inferiores (abaixo de cinco) foram as seguintes: Q15 $(4,442)$, Q17 $(3,884)$, Q18 $(3,093)$ e Q19 $(3,651)$.

Quanto ao domínio psicológico, as questões que apresentaram médias superiores (maiores que sete) foram as seguintes: Q20 (7,558), Q22 $(7,395)$ e Q23 $(7,302)$. 
O domínio social apresentou quatro questões com médias abaixo de cinco. São elas: Q26 (3,395), Q 27 (2,140), Q30 (3,372) e Q31 (2,047).

No domínio organizacional - atividade docente, as questões que apresentaram médias superiores a sete foram a Q32 e a Q40, com 7,047 e 8,233, respectivamente. As questões Q33 e Q41 apresentaram médias inferiores a cinco: 4,349 e 4,977 nessa ordem.

O domínio psicológico e o domínio social apresentaram, respectivamente, a menor $(3,192)$ e a maior $(6,819)$ média de satisfação.

A menor média apresentada nesta pesquisa foi de 2,047, dada à Q30 que se refere ao valor do auxílio transporte. Já a maior, 8,233, foi atribuída à Q40 que trata do relacionamento professoraluno.

\section{CONCLUSÃO}

O presente estudo teve como objetivo central analisar o grau de satisfação dos professores da Rede Federal de Educação Básica, Técnica e Tecnológica que participaram do II Fórum Mundial de Educação Profissional e Tecnológica (Florianópolis em 2012), diante dos impactos da expansão da Rede no Brasil sobre a Qualidade de Vida no Trabalho. A pesquisa foi realizada com base nos fatores de satisfação quanto aos aspectos biológicos, psicológicos, sociais e organizacionais e às práticas docentes.

Entende-se que os objetivos foram atingidos, pois verificou-se a importância dos aspectos da qualidade de vida no trabalho orientados para a qualidade da educação sob a percepção dos professores da Rede Federal de Educação Profissional e Tecnológica.

A partir do resultado dos questionários respondidos pelos professores com relação aos domínios: organizacional, biológico, psicológico e social, no que tange, especificamente, às atividades docentes, infere-se que as práticas de qualidade de vida no trabalho são fundamentais para que os professores da Rede se façam envolvidos e comprometidos e assim, possam desenvolver melhor suas atividades docentes de acordo com os princípios norteadores da docência.

Os resultados apresentados tiveram como base a abordagem biopsicossocial e organizacional (BPSO-96) de Limongi-França. As ações de Qualidade de Vida no Trabalho demonstram contemplar, predominantemente, o domínio psicológico da atividade docente, seguido pelo domínio organizacional, que apresentaram médias superiores a sete. Os domínios que apresentaram médias menores que cinco foram o biológico e o social. Isso demonstra insatisfação por parte dos professores participantes da pesquisa.

Nesse contexto, no domínio organizacional, observa-se que os respondentes apresentaram um grau de satisfação com média de 6,093, com destaque para a atuação do departamento de recursos humanos no campus e para os programas sociais destinados aos alunos carentes.

No domínio biológico a média geral foi de 4,300. Esse valor demonstra a insatisfação dos participantes com os seguintes itens: atendimento ambulatorial no campus, a qualidade da alimentação fornecida pelo campus, a atuação da comissão interna de prevenção de acidentes, qualidade dos programas de prevenção da vida e da integridade física, bem como com a promoção da saúde dos servidores e dos alunos. 
O domínio psicológico apresentou média geral de satisfação em relação a todas as suas variáveis de 6,819. Obtiveram as maiores médias de satisfação desse domínio os itens referentes à confiança nos critérios de seleção dos professores e ao clima de camaradagem entre os professores da área técnica e do núcleo comum.

No domínio social, todos os aspectos pesquisados apontaram uma média de 3,192. Esse resultado se insere na faixa de insatisfação e pode ser decorrente da falta da adoção de políticas sociais. A variável que apresentou a menor média foi o auxílio transporte. Vale destacar que esse resultado pode ser uma oportunidade para direcionar ações que proporcionem ao campus, melhorias quanto aos benefícios de auxílio pré-escolar e aos valores do auxílio alimentação e do auxílio transporte.

A atividade docente apresentou a média geral de 6,072 no conjunto de todas as variáveis que a compõem. Dessa forma, observa-se que os professores respondentes apresentaram níveis de satisfação em relação a ela. Nesse domínio, destaca-se que a variável que apresentou a maior média foi a relação professor-aluno.

Esses alunos devem proporcionar aos seus professores recordações de sua própria história social e acadêmica, fortalecendo, assim, essa identificação e, ao mesmo tempo, esses docentes simbolizam para esses alunos uma perspectiva de futuro, um exemplo de vida, uma suposição de que são donos do saber, o que também proporciona esse enlace (OLIVEIRA et al., 2012).

A quantidade de alunos por sala de aula $(7,047)$ merece destaque, uma vez que a média geral $(6,072)$ só não foi maior devido à baixa satisfação dos professores em relação à estrutura dos laboratórios $(4,349)$ e ao ambiente de descanso dos professores $(4,977)$.

Entre os cinco domínios avaliados, constatou-se que o domínio social foi o que apresentou o menor índice de satisfação, enquanto que o domínio psicológico foi o que apresentou maior satisfação.

Embora os resultados não possam ser generalizados para o expressivo universo de professores do Ensino Técnico dos Institutos Federais, os achados deste estudo demonstram a necessidade de alinhamento quanto à política de gestão de benefícios e apoio familiar e comunitários no grupo pesquisado, revelando a qualidade da relação ensino-aprendizado neste cenário.

\section{REFERÊNCIAS BIBLIOGRÁFICAS}

1. BERTUOL, F.P.; MARTINS, P.L.O. A qualidade de vida docente em cursos de licenciatura. Revista Olhar de professor, Ponta Grossa, v. 12, n. 2, p. 257-285, 2009.

2. BRASIL, Instituto Nacional de Estudos e Pesquisas Educacionais Anísio Teixeira. Censo Escolar 2014. Brasília, 2015. Disponível em: <http://portal.inep.gov.br/web/educacenso/educacen so>. Acesso em 04 de maio, 2015.

3. BRASIL. Ministério da Educação. O Plano de desenvolvimento da educação: razões, princípios e programas. Brasília, 24 abr. 2007.

4. BRASIL, Ministério do Planejamento, Orçamento e Gestão Secretaria de Gestão Pública. Boletim Estatístico de Pessoal e Informações Organizacionais. Brasília, jan., 2015, v. 19, n. 225. Disponível em: <http://www.planejamento.gov.br/secretarias/upload/Arquivos/servi 
dor/publicacoes/boletim_estatistico_pessoal/2015/Bol225_Jan2015_parte_I_03.pdf>. Acesso em 04 de maio, 2015.

5. BRASIL. Lei no 11.892, de 29 de dezembro de 2008. Institui a Rede Federal de Educação Profissional, Científica e Tecnológica, cria os Institutos Federais de Educação, Ciência e Tecnologia, e dá outras providências. Diário Oficial da União.

6. BURNIER, S. et al. História de vida de professores: o caso da educação profissional. Revista Brasileira de Educação, Rio de Janeiro, v. 12, n. 23, p. 343-358, maio/ago., 2007.

7. CARNOY, M. Higher Education and Economic Development: India, China, and the 21st Century. THE PAN ASIA CONFERENCE: FOCUS ON ECONOMIC CHALLENGES. Stanford Center for International Development. Working Paper N. 297. Stanford University, 31, 2006.

8. LIMONGI-FRANÇA, A.C. Indicadores empresariais de qualidade de vida no trabalho: um estudo comparativo entre satisfação dos empregados e esforço empresarial nas empresas com certificação ISO 9000. 1996. 296f Tese (Doutorado em Administração de Empresas) Faculdade de Economia e Administração e Contabilidade da Universidade de São Paulo, São Paulo, 1996.

9. LIMONGI-FRANÇA, A.C.; RODRIGUES, A.L. Stress e trabalho: uma abordagem psicossomática. 4 ed. São Paulo: Atlas, 2009. 192p.

10. LIMONGI-FRANÇA, A.C. Qualidade de vida no trabalho - QVT: conceitos e práticas nas empresas da sociedade pós-industrial. 2. ed. São Paulo: Atlas, 2009.

11. LIMONGI-FRANÇA, A.C. Saúde com qualidade de vida organizacional e pessoal de onde vem e para onde vai este caminho de sustentabilidade? In: MARRAS, J. P. (Org.) Gestão estratégica de pessoas: conceitos e tendências. São Paulo: Saraiva, 2010. p. 227-250.

12. MACHADO, L. R. S. Diferenciais inovadores na formação de professores para a educação profissional. Revista Brasileira da Educação Profissional e Tecnológica, Brasília, v. 1, n. 1, p. 822, jun., 2008.

13. MARCONI, M.A.; LAKATOS, E.M. Fundamentos de metodologia científica. 6 ed. São Paulo: Atlas, 2009.

14. OLIVEIRA, M.A. L. AS8000: o modelo ISO 9000 aplicado à responsabilidade social. Rio de Janeiro: Qualitymark, 2003.

15. OLIVEIRA, R.R. Qualidade de vida no trabalho - QVT e responsabilidade social empresarial RSE: um estudo sobre a satisfação de QVT com funcionários voluntários em programas RSE. 2008 Dissertação (Mestrado em Administração), Faculdade de Ciências Administrativas da Universidade Metodista de São Paulo, São Bernardo do Campo, 2008.

16. OLIVEIRA, R.R. et al. Qualidade de Vida no Trabalho: estudo com docentes de um Instituto Federal em Relação a Educação Profissional de Jovens e Adultos. In: ALMEIDA, I. B. P.; SANTOS, S. S. (Org.) Educação Tecnológica: reflexões, teorias e práticas. Jundiaí: Paco Editorial, p. 185-202, 2012.

17. PACHECO, E.M.; SILVA, C.J.R. Institutos Federais: um futuro por armar. In: SILVA, C. J. R. (Org.) Institutos Federais lei 11.892, de 29/11/2008: comentários e reflexões. Natal: IFRN, 2009. P. 7-11.

18. SÃO PAULO. Secretaria do Emprego e Relações do Trabalho. A importância do ensino técnico e da capacitação profissional. São Paulo, 2012 Disponível em: <http://www.emprego.sp.gov. 
$\mathrm{br} /$ noticias/artigos/a-importancia-do-ensino-tecnico-e-da-capacitacao-profissional> Acesso em 20 ago., 2012.

19. SILVA, C.O.B. A Docência na Educação Profissional para Jovens e Adultos: desafios e perspectivas no espaço de inquietações. In: VI SEMANA DE EXTENSÃO, PESQUISA E PÓSGRADUAÇÃO DO UNIRITTER, 6., 2010, Porto Alegre. Anais... Porto Alegre: UNIRITTER, 2010. Disponível em: <http://www.uniritter.edu.br/eventos/sepesq/vi_sepesq/arquivosPDF/27973 /2359/com_identificacao/artigo_vfinal.pdf>. Acesso em: 01 de set. 2012.

20. SOARES, A.S. A educação profissional e o professor: fazeres e saberes necessários. In. SEMINÁRIO NACIONAL DE EDUCAÇÃO PROFISSIONAL E TECNOLÓGICA - SENEPT, 1., 2008, Belo Horizonte. Anais... Belo Horizonte: CEFET-MG, 2008.

21. STEFANO, S.R. Satisfação da qualidade de vida no trabalho com relação aos fatores biopsicossociais e organizacionais: um estudo comparativo entre docentes das universidades pública e privada. Revista Gerenciais, São Paulo, v.5, p. 35-44, 2006.

22. STEPHEN, A.; DHANAPAL, D. Quality of Work Life in Small Scale Industrial Units: Employers and Employees Perspectives. European Journal of Social Sciences, Mahé, v. 28, n. 2, p. 262-271, 2012.

23. TARDIF, M. Saberes docentes e formação profissional. 2 ed. Petrópolis: Vozes, 2002.

24. WALTON, R. Criteria For Quality Life. In DAVIS, L. A. B. The Quality of working life: problems, prospects and state of the art. New York: The Free Press, 1975. 